\title{
DESEMPENHO TÉRMICO DE UMA RESIDÊNCIA COM DIFERENTES CONFIGURAÇÕES DE PAREDES TROMBE: ESTUDO PARA CURITIBA - PR
}

\author{
Thermal Performance of a Residence with different configurations of Trombe \\ Walls: Study for Curitiba - PR
}

\author{
Clarissa Sartori ZIEBELL ${ }^{1}$, José Luis Farinatti AYMONE ${ }^{2}$
}

Recebido em 28 de fevereiro de 2019; aceito em 02 de agosto de 2019; disponível on-line em 03 de junho de 2020.

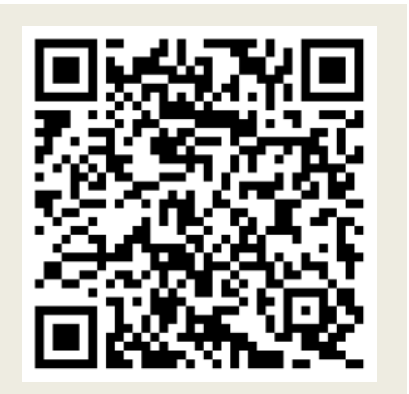

PALAVRAS CHAVE:

Paredes Trombe;

Simulação computacional; Desempenho térmico; Arquitetura solar passiva; Custos.

\section{KEYWORDS:}

Trombe wall;

Computer Simulation;

Thermal Performance;

Passive solar architecture;

Costs.

RESUMO: O uso de tecnologias passivas para climatizar os ambientes, tal como a parede Trombe, é uma forma reconhecida para minimizar o gasto energético com a climatização artificial do ar. Este artigo tem como objetivo avaliar, através do software EnergyPlus, a influência de diferentes paredes Trombe em uma edificação residencial, considerando o contexto climático de Curitiba, cidade que apresenta baixas temperaturas médias mensais. Para uma análise mais completa a respeito das vantagens em utilizar uma parede Trombe, foi realizado ainda um levantamento de custo do sistema. A partir das análises realizadas, constatou-se que o uso de paredes Trombe permitiu a elevação das temperaturas internas, especialmente quando foram abertas as janelas de ventilação interna. Contudo, nos dias de temperaturas externas muito baixas o uso da parede Trombe não foi suficiente para garantir o conforto térmico dos ocupantes. Durante o verão, a parede Trombe não provocou desconforto térmico por calor. Apesar de ter sua eficiência comprovada, verificou-se que o preço da esquadria pode ser um impedimento para a adoção do sistema. Sendo assim, ressalta-se a importância de um estudo a respeito do desempenho da parede Trombe combinado com outras estratégias bioclimáticas. Do contrário, o uso de climatização artificial será necessário.

ABSTRACT: The use of passive technologies to climatize the environment, as the Trombe wall, is a recognized way to minimize energy waste with artificial air conditioning This paper aims to evaluate, through use of the software EnergyPlus, the influence of different Trombe walls on a residential building, considering the climate context of Curitiba, city where the monthly mean temperatures are low. For a more complete analysis of the advantages in using a Trombe wall, the cost of the system was also verified. From the analyzes carried out, the use of Trombe walls was found to be an alternative to allow the increase of internal temperatures, especially when the internal ventilation windows where opened. However, on days of very low external temperatures the use of the Trombe wall was not enough to guarantee the thermal comfort of the occupants. During the summer, the Trombe wall did not cause thermal discomfort by heat. Despite its proven efficiency, the window price was found to be an impediment for the system adoption. Thus, is emphasized the importance of a study on the performance of the Trombe wall combined with other bioclimatic strategies. Otherwise, the use of artificial air conditioning will be necessary.

\section{* Contato com os autores:}

${ }^{1}$ e-mail: clarissa.ziebell@ufrgs.br (C. S. Ziebell)

Arquiteta, doutoranda, Professora Assistente da Universidade Federal do Rio Grande do Sul (UFRGS)

2e-mail: aymone@ufrgs.br (J. L. F. Aymone )

Engenheiro Civil, doutor, Professor Titular da Universidade Federal do Rio Grande do Sul (UFRGS) 


\section{INTRODUÇÃO}

Desde a crise de petróleo tem sido impulsionado o desenvolvimento do uso de energias limpas e renováveis (Lamberts e Triana, 2007). Atualmente, os graves problemas ambientais do planeta tornam urgente a necessidade de introdução de uma cultura arquitetônica que leve em consideração os condicionantes ambientais (Monteiro et al., 2015). Dentro deste contexto, o uso do sistema solar passivo aparece como uma alternativa para minimizar o consumo de energia com a climatização artificial do ar. Como exemplo de sistema solar passivo bastante conhecido tem-se a parede Trombe. O sistema da parede Trombe foi primeiramente patenteado por E. L. Morse, em 1881. Posteriormente, em 1957, o conceito foi desenvolvido por Felix Trombe e Jacques Michel, no sul da França (BRIGA-SÁ et al., 2014; MEDONÇA, 2005). A parede Trombe consiste em uma parede maciça voltada à orientação de maior insolação (geralmente pintada de preto), uma camada de ar e uma esquadria. Apesar de ter sido concebido originalmente para o aquecimento, o sistema de paredes Trombe também pode ser utilizado para resfriar o ambiente através da renovação natural do ar. Neste caso, uma abertura na parede oposta à parede Trombe permite a entrada do ar, que é posteriormente removido devido à convecção forçada gerada no interior da chaminé.

No Brasil, ainda são poucos os estudos a respeito de paredes Trombe. Como exemplo, há o trabalho de Suzuki (2012), que estudou o potencial de utilização de paredes Trombe na cidade de Curitiba (PR). Para o estudo, a autora construiu dois protótipos, um com e outro sem a parede Trombe. Como resultado das medições, Suzuki (2012) constatou que no inverno a temperatura mínima no interior do protótipo com a parede Trombe chegou a ficar $4,4^{\circ} \mathrm{C}$ mais alta do que a temperatura externa, enquanto que no outro protótipo a maior diferença foi de $2,8^{\circ} \mathrm{C}$. Ainda, que a melhor configuração para o inverno é manter a abertura superior da esquadria fechada e as demais abertas. No verão, o sistema também apresentou bons resultados e a melhor configuração foi aquela onde todas as aberturas estavam fechadas.

Este trabalho pretende aprofundar os estudos de Suzuki (2012), porém com o uso de simulação computacional por meio da utilização de modelos gerados com o programa EnergyPlus. Assim, torna-se possível a análise simultânea de diferentes características da parede Trombe, o que facilita a escolha da melhor solução de paredes Trombe para uma determinada edificação. Ainda, ao invés de um protótipo, o modelo estudado neste presente trabalho consiste em uma pequena habitação, onde é considerada a interação do usuário ao longo do dia. Ao final do trabalho, analisa-se ainda o custo do sistema, a fim de verificar se o seu desempenho térmico justificaria tal investimento.

\section{OBJETIVO}

O objetivo deste estudo é avaliar, através de simulação computacional, a influência de diferentes paredes Trombe em uma edificação residencial inserida em Curitiba-PR. São avaliadas paredes Trombe ventiladas e não ventiladas e dois diferentes tipos de acabamentos. Ainda, é levado em consideração a interação com o usuário. Para uma análise mais completa a respeito das vantagens em utilizar uma parede Trombe, é feito um levantamento de custo do sistema.

\section{CONTEXTUALIZAÇÃO}

No projeto de uma parede Trombe são muitas as variáveis que devem ser definidas, tais como o material e a espessura da parede maciça, a distância entre o vidro e esta parede, o tipo de vidro, o tamanho das aberturas, entre outros. Para tanto, é necessário conhecer o clima local e, consequentemente, a necessidade de aquecimento ou de resfriamento do ambiente onde a parede Trombe será inserida. No caso do Brasil, devido à variedade de tipos de climas 
encontrados, essa questão ganha muita importância, já que não se pode definir um modelo como o ideal para todas as regiões. A seguir, são apresentadas diferentes configurações para a parede Trombe e estudos dessas configurações aplicadas a climas brasileiros.

\subsection{VARIÁVEIS DAS PAREDES TROMBE}

A parede maciça do sistema de parede Trombe geralmente é construída com pedra, tijolo ou concreto (Abbassi et al., 2014). Ela armazena calor vindo do sol durante o dia e libera-o para o interior durante a noite. Este calor é conduzido devagar através da parede para a superfície interna e então para o ambiente por radiação e convecção (Yedder e Bilgen, 1990). Quando a parede Trombe está configurada para o aquecimento, $\mathrm{o}$ ar vindo do ambiente interno entra no canal pela abertura inferior, é aquecido pela parede, e então sobe devido à força de empuxo. Em seguida, o ar retorna ao interior do ambiente através da abertura superior. Quando a temperatura externa for moderada (por exemplo, maior do que $10^{\circ} \mathrm{C}$ ), o ar vindo da abertura inferior também pode ser oriundo do meio externo (Gan, 1998).

Apesar de ser considerada como um sistema de aquecimento solar passivo, a parede Trombe ventilada também permite fazer a renovação do ar através do efeito chaminé (Pinto e Dias, 2015). Sendo assim, ela pode ser utilizada no modo resfriamento, quando o ar aquecido no interior do canal é conduzido para o exterior por meio de uma abertura superior no painel envidraçado (Gan, 1998) (Figura 1). Nesse caso o calor é liberado para o ambiente externo, o que incrementa a ventilação do ambiente interno (Cavalcanti et al., 2011).

\subsection{PAREDES TROMBE NO BRASIL}

$\mathrm{Na}$ Europa, onde ocorrem temperaturas muito baixas durante o inverno, são encontrados diversos estudos a respeito da parede Trombe (GAN, 1998; GOMES, 2011). Porém, o clima brasileiro possui características completamente diferentes, e por isso são importantes análises em todas as Zonas Bioclimáticas. Além do trabalho de Suzuki (2012), mencionado na introdução, também são encontrados outros trabalhos que estudaram o uso da parede Trombe em climas brasileiros. Figueira (2005) analisou o comportamento térmico de um coletor solar acumulador, localizado no Laboratório de Energia Solar da Universidade Federal do Rio Grande do Sul (UFRGS) em Porto Alegre, e desenvolveu uma metodologia para medir a sua eficiência diária no inverno.
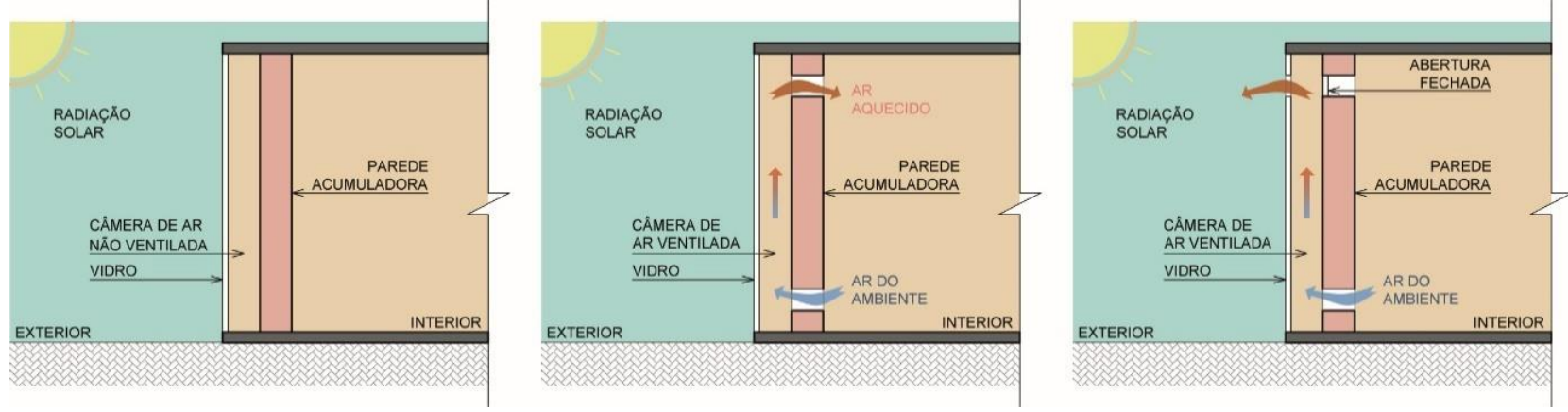

FIGURA 1: Esquemas de operação: (A) Parede Trombe não ventilada; (B) Parede Trombe no modo inverno com termo-circulação do ar; (C) Parede Trombe no modo verão com ventilação cruzada.

FONTE: Adaptado de Stazi et al. (2012, pág. 218). 
Cavalcanti et al. (2011) avaliou, através do software EnergyPlus, o desempenho térmico de uma habitação de interesse social munida de uma parede Trombe na cidade de São Carlos-SP. A parede Trombe foi analisada com uma configuração para o inverno e outra para o verão. Em ambos os casos, os ambientes com a parede Trombe levaram, na maior parte do dia, à temperaturas dentro da faixa de conforto térmico, o que não ocorreu com o ambiente que não possuía este sistema.

Cavalcanti (2013) estudou o potencial de utilização da parede Trombe, tanto para aquecimento quanto para resfriamento, em diversas cidades brasileiras e utilizando diferentes configurações. Para tanto, foi utilizado o software EnergyPlus. A fachada oposta à parede Trombe possuía um elemento de sombreamento de 3 metros de largura e uma abertura inferior de entrada de ar para ventilação. O modelo foi simulado para uma cidade de cada uma das oito Zonas Bioclimáticas brasileiras (ZB). O desempenho destes modelos foi comparado com um modelo de referência (sem parede Trombe e com janela tradicional). Como resultado do trabalho de Cavalcanti (2013), foi constatado que, com exceção de Cuiabá (ZB 7) e Belém (ZB 8), o sistema de paredes Trombe pode ser utilizado em todas as demais cidades. No geral, os modelos que se mostraram com um número menor de horas de desconforto térmico, possuem a espessura da parede de 0,45 $\mathrm{m}$ e área das aberturas equivalente a 3\% da área da parede Trombe.

Bianco (2016) analisou o desempenho térmico de uma parede Trombe tanto para aquecimento quanto para arrefecimento no clima da cidade de São Paulo. A análise foi realizada a partir da construção e monitoramento de dois protótipos, um sem (protótipo de referência) e outro com a parede Trombe. Os protótipos foram construídos na Cidade Universitária da Universidade de São Paulo (USP). O protótipo com a parede Trombe possuía duas aberturas no vidro (para entrada e saída do ar), quatro aberturas de ventilação na parede da fachada norte (duas superiores e duas inferiores) e uma porta na fachada sul. Com exceção das aberturas no vidro, o protótipo de referência possuía as mesmas aberturas que o protótipo com a parede Trombe. Os resultados dos experimentos indicaram o potencial de adoção da parede Trombe para obter conforto térmico nas situações estudadas pela autora.

\section{METODOLOGIA}

O método de pesquisa deste trabalho consiste na montagem de um modelo de simulação que permita avaliar a influência de uma parede Trombe sobre o conforto térmico de um ambiente de uma residência, considerando o clima de Curitiba. O software selecionado para as simulações computacionais foi o EnergyPlus financiado pelo Departamento de Energia dos Estados Unidos e gerenciado pelo National Renewable Energy Laboratory (NREL) (EnergyPlus, 2018). Este software permite simular um edifício através da entrada de dados como geometria, materiais, ar condicionado, iluminação, entre outros, permitindo, assim, a fácil alteração de diversos parâmetros do modelo. A escolha deste programa se deve ainda ao fato de que o algoritmo utilizado pelo EnergyPlus para modelar a convecção do ar dentro da zona de uma parede Trombe não ventilada foi validado através de um trabalho experimental por Ellis (2003).

A geometria do modelo foi desenvolvida no software SketchUp 2017 (através do plugin Euclides). Posteriormente, diversos dados foram inseridos por meio do EnergyPlus, versão 8.7. O modelo definido para as simulações consiste em uma pequena habitação com um dormitório (Figura 2). Optou-se por uma edificação de pequeno porte a fim de simplificar as simulações, possibilitando assim, maior agilidade na variação dos parâmetros e na análise dos resultados. 
No EnergyPlus, foram definidas cinco zonas térmicas: uma para o dormitório, uma para o banheiro, uma para a sala de estar e jantar e para a circulação, uma para a cozinha e para a lavanderia e uma para a cobertura (Figura 3). As paredes Trombe, quando existentes nos modelos, foram posicionadas na parede Norte do dormitório e da sala de estar e jantar. Na Figura 3 o eixo verde indica a orientação do Norte.

A primeira edificação simulada não possui a parede Trombe. Dessa forma, os resultados desta primeira simulação servem de parâmetro de referência nas análises de conforto térmico. A parede Trombe é inserida a partir da segunda simulação. Para tanto, são desenhadas duas novas zonas representando as esquadrias das paredes Trombe (Figura 3-C). Ressalta-se na Figura 3-C a parede Trombe colocada sobre as duas paredes sem aberturas apresentadas na Figura 3-B.

$\mathrm{Na}$ segunda simulação a parede Trombe é inserida com pintura da parede maciça na cor preta. $\mathrm{Na}$ terceira simulação a cor preta é trocada por uma película seletiva. Por fim, na quarta simulação, é adicionada a ventilação interna. Nesse caso, o acabamento da superfície externa da parede maciça é de tinta preta e a ventilação ocorre entre o canal e o ambiente interno (Figura 4).

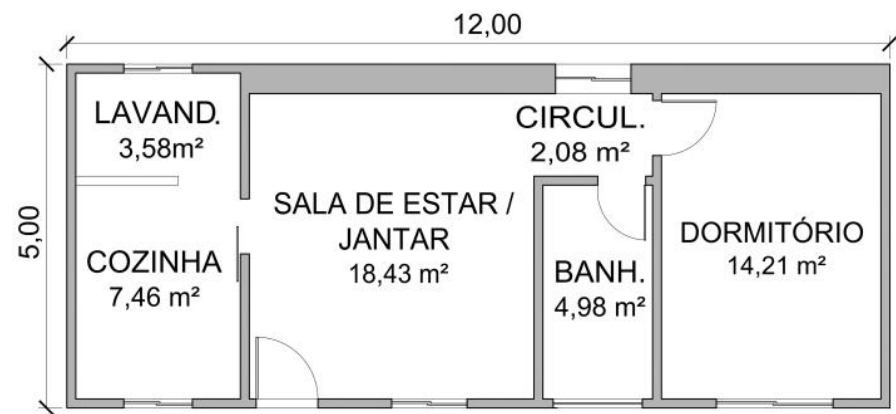

FIGURA 2: Planta-baixa da edificação simulada.

FONTE: Autoria Própria.
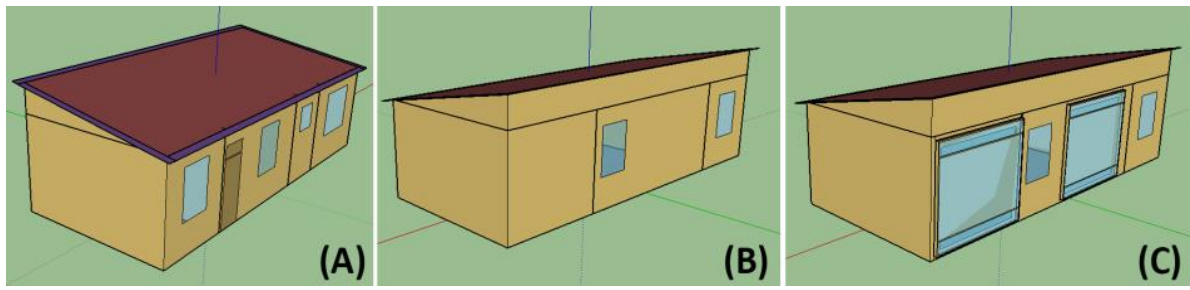

FIGURA 3: Geometria do modelo simulado no EnergyPlus. (A) Fachada sul; (B) Fachada norte do modelo sem paredes Trombe; (C) Fachada norte do modelo com paredes Trombe.

FONTE: Autoria Própria.

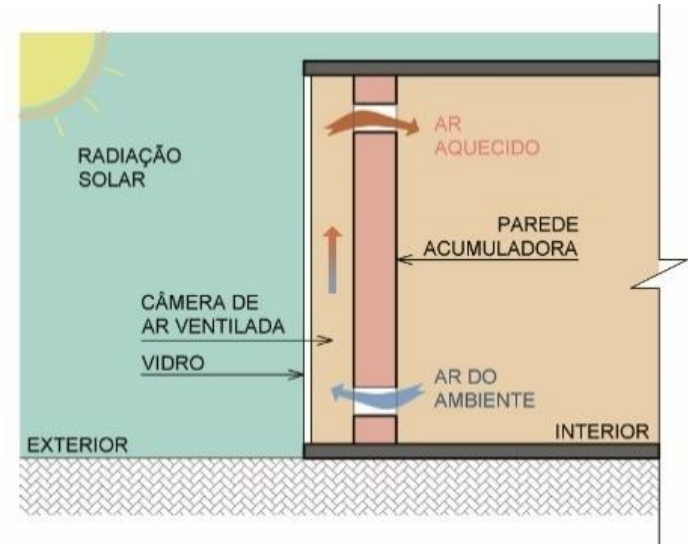

FIGURA 4: Funcionamento da ventilação na quarta simulação.

FONTE: Autoria Própria. 


\subsection{LOCALIZAÇÃO E CLIMA}

Curitiba (25'42" Sul, 49'16" $24^{\circ}$ Oeste) é a capital do Paraná, estado da região sul do Brasil. Caracteriza-se por ter verões com temperatura máxima acima de $20^{\circ} \mathrm{C}$ e invernos com temperaturas médias em torno de $15^{\circ}$ (Rossi et al., 2009). De acordo com ABNT (2005b), as estratégias de projeto arquitetônico para atingir o conforto térmico de Curitiba (Zona Bioclimática 1) consistem no aquecimento solar da edificação e no uso de vedações internas pesadas (inércia térmica). A parede Trombe para aquecimento se encaixa, portanto, na recomendação de utilização do aquecimento solar. Para que as características do clima fossem levadas em conta na simulação, foi utilizado o arquivo climático disponível em LabEEE (2018).

\subsection{CARACTERÍSTICAS CONSTRUTIVAS}

As paredes da residência são de tijolos maciços, revestidas com argamassa e pintadas de branco em ambos os lados. Com exceção das paredes externas da sala de estar e jantar e do dormitório, que possuem $45 \mathrm{~cm}$, todas as demais parede externas possuem $25 \mathrm{~cm}$ de espessura. As paredes da sala de estar e jantar e do dormitório são mais espessas a fim de que a massa térmica da parede não influencie na avaliação do desempenho da parede Trombe. As paredes internas possuem $15 \mathrm{~cm}$ de espessura. A cobertura é formada por uma laje de concreto e um telhado revestido com telhas de fibrocimento. Por fim, o contrapiso é de concreto, revestido por um piso cerâmico. Todas as janelas possuem vidro simples incolor de $3 \mathrm{~mm}$ (Tabela 1). As portas são de madeira, pintadas de branco. A Tabela 1 mostra as características dos vidros, enquanto que a Tabela 2 detalha as características dos materiais utilizados na construção das superfícies.

Os valores de transmitância térmica e de capacidade térmica apresentados na Tabela 3 levaram em consideração propriedades térmicas dos materiais obtidas em ABNT (2005a), Cavalcanti e Caran (2013). Os cálculos foram realizados conforme metodologia descrita em ABNT (2005a).

\begin{tabular}{|c|c|c|c|}
\hline Tipo de dados ópticos & $\begin{array}{l}\text { Média } \\
\text { Espectral }\end{array}$ & Tipo de dados ópticos & $\begin{array}{l}\text { Média } \\
\text { Espectral }\end{array}$ \\
\hline Espessura (m) & 0,03 & $\begin{array}{l}\text { Refletância visível na face frontal e } \\
\text { posterior (Incidência Normal) }\end{array}$ & 0,081 \\
\hline Transmitância Solar (Incidência Normal) & 0,837 & $\begin{array}{c}\text { Transmitância no Infravermelho (Incidência } \\
\text { Normal) }\end{array}$ & 0 \\
\hline $\begin{array}{l}\text { Refletância solar na face frontal e } \\
\text { posterior (Incidência Normal) }\end{array}$ & 0,075 & $\begin{array}{c}\text { Emissividade Hemisférica no Infravermelho } \\
\text { na face frontal e posterior }\end{array}$ & 0,84 \\
\hline $\begin{array}{c}\text { Transmitância Visível (Incidência } \\
\text { Normal) }\end{array}$ & 0,898 & Condutividade (W/mK) & 0,9 \\
\hline
\end{tabular}


TABELA 2: Propriedades dos materiais utilizados nas construções das superfícies.

\begin{tabular}{cccc}
\hline Elemento & Composição & $\begin{array}{c}\text { Transmitância Térmica } \\
\mathbf{W} /\left(\mathbf{m}^{2} \mathbf{K}\right)\end{array}$ & $\begin{array}{c}\text { Capacidade Térmica } \\
\mathbf{~} \mathbf{k J} /\left(\mathbf{m}^{2} \mathbf{K}\right)\end{array}$ \\
\hline $\begin{array}{c}\text { Paredes externas } \\
(45 \mathrm{~cm})\end{array}$ & $\begin{array}{c}19 \mathrm{~cm} \text { tijolo }+ \\
2 \mathrm{~cm} \text { de argamassa } \\
19 \mathrm{~cm} \text { tijolo }+ \\
2,5 \mathrm{~cm} \text { de reboco }\end{array}$ & 1,60 & 680,59 \\
\hline $\begin{array}{c}3 \mathrm{~cm} \text { de reboco }+ \\
19 \mathrm{~cm} \text { tijolo }+ \\
3 \mathrm{~cm} \text { de reboco }\end{array}$ & 2,38 & 391,18 \\
\hline $\begin{array}{c}3 \mathrm{~cm} \text { de reboco }+ \\
9 \mathrm{~cm} \text { tijolo }+ \\
3 \mathrm{~cm} \text { de reboco }\end{array}$ & 3,15 & 246,91 \\
\hline $\begin{array}{c}\text { Paredes externas internas } \\
(15 \mathrm{~cm})\end{array}$ & $\begin{array}{c}\text { Ar }+ \\
\text { Cobertura }\end{array}$ & 1,80 & 301,4 \\
\hline
\end{tabular}

FONTE: Autoria Própria.

\subsection{GANHOS INTERNOS}

Os ganhos internos da residência foram definidos conforme o mínimo estabelecido pelo Regulamento Técnico da Qualidade para o Nível de Eficiência Energética de Edificações Residenciais (RTQ-R) (INMETRO, 2012). Esses incluem a ocupação da edificação, o uso da iluminação artificial, o uso de equipamentos e as taxas metabólicas. Segundo o RTQ-R (INMETRO, 2012), para os dormitórios, o padrão mínimo de ocupação deve ser de duas pessoas e a sala deve ser usada por todos habitantes da Unidade Habitacional Autônoma. Esses devem respeitar a Tabela 3. O padrão de iluminação é apresentado na Tabela 4 , onde os valores $100 \%$ representam os horários de uso da iluminação e os valores $0 \%$ representam que a iluminação do ambiente está desligada. As densidades de potência instalada (DPI) de iluminação devem ser de $5 \mathrm{~W} / \mathrm{m}^{2}$ para os dormitórios e de $6 \mathrm{~W} / \mathrm{m}^{2}$ para a sala.

TABELA 3: Padrão de ocupação para dias de semana e final de semana.

\begin{tabular}{|c|c|c|c|c|c|c|c|}
\hline \multicolumn{4}{|c|}{ Dormitórios } & \multicolumn{4}{|c|}{ Sala de Estar e Jantar } \\
\hline Hora & $\begin{array}{c}\text { Dia de } \\
\text { semana } \\
(\%)\end{array}$ & Hora & $\begin{array}{c}\text { Final de } \\
\text { semana } \\
(\%)\end{array}$ & Hora & $\begin{array}{c}\text { Dia de } \\
\text { semana } \\
(\%)\end{array}$ & Hora & $\begin{array}{c}\text { Final de } \\
\text { semana } \\
(\%)\end{array}$ \\
\hline $1 \mathrm{~h}-7 \mathrm{~h}$ & 100 & $1 h-9 h$ & 100 & $1 h-13 h$ & 0 & $1 h-10 h$ & 0 \\
\hline $8 h-20 h$ & 0 & $10 \mathrm{~h}$ & 50 & $14 h-18 h$ & 25 & $11 \mathrm{~h}$ & 25 \\
\hline $21 \mathrm{~h}$ & 50 & $11 h-20 h$ & 0 & $19 \mathrm{~h}$ & 100 & $12 \mathrm{~h}$ & 75 \\
\hline \multirow[t]{6}{*}{$22 h-24 h$} & 100 & $21 \mathrm{~h}$ & 50 & $20 h-21 h$ & 50 & $13 \mathrm{~h}$ & 0 \\
\hline & & $22 \mathrm{~h}-24 \mathrm{~h}$ & 100 & $22 h-24 h$ & 0 & $14 \mathrm{~h}$ & 75 \\
\hline & & & & & & $15 h-17 h$ & 50 \\
\hline & & & & & & $18 h-19 h$ & 25 \\
\hline & & & & & & $20 h-21 h$ & 50 \\
\hline & & & & & & $22 h-24 h$ & 0 \\
\hline
\end{tabular}




\begin{tabular}{|c|c|c|c|c|c|c|c|}
\hline \multicolumn{4}{|c|}{ Dormitórios } & \multicolumn{4}{|c|}{ Sala de Estar e Jantar } \\
\hline Hora & $\begin{array}{c}\text { Dia de } \\
\text { semana } \\
(\%)\end{array}$ & Hora & $\begin{array}{c}\text { Final de } \\
\text { semana } \\
(\%)\end{array}$ & Hora & $\begin{array}{c}\text { Dia de } \\
\text { semana } \\
(\%)\end{array}$ & Hora & $\begin{array}{c}\text { Final de } \\
\text { semana } \\
(\%)\end{array}$ \\
\hline $1 \mathrm{~h}-6 \mathrm{~h}$ & 0 & $1 \mathrm{~h}-8 \mathrm{~h}$ & 0 & $1 \mathrm{~h}-16 \mathrm{~h}$ & 0 & $1 \mathrm{~h}-10 \mathrm{~h}$ & 0 \\
\hline $7 \mathrm{~h}$ & 100 & $9 \mathrm{~h}$ & 100 & $17 h-21 h$ & 100 & $11 \mathrm{~h}-12 \mathrm{~h}$ & 100 \\
\hline $8 h-20 h$ & 0 & $10 h-20 h$ & 0 & $22 h-24 h$ & 0 & $13 h-16 h$ & 0 \\
\hline $21 h-22 h$ & 100 & $21 h-22 h$ & 100 & & & $17 h-21 h$ & 100 \\
\hline $23 h-24 h$ & 0 & $23 h-24 h$ & 0 & & & $22 h-24 h$ & 0 \\
\hline
\end{tabular}

Em cada ambiente é comum o desenvolvimento de um tipo de atividade diferente. Por essa razão, recomenda-se uma atividade metabólica diferente para salas e dormitórios. O calor produzido para a sala deve ser de $60 \mathrm{~W} / \mathrm{m}^{2}$ e para o dormitório deve ser de 45 $\mathrm{W} / \mathrm{m}^{2}$. O calor produzido por área de pele (considerando área igual a 1,80 $\mathrm{m}^{2}$ ) deve ser de $108 \mathrm{~W}$ para a sala e de $81 \mathrm{~W}$ para o dormitório (INMETRO, 2012). Também deve-se informar a potência dos equipamentos para a sala, que deve ser de $1,5 \mathrm{~W} / \mathrm{m}^{2}$ durante todo o dia.

Para complementar o modelo, foi inserida uma massa interna, correspondente aos móveis, totalizando uma área de $15 \mathrm{~m}^{2}$. Essa massa irá influenciar nos cálculos de transferência de calor (U.S. Department of Energy, 2016b).

\subsection{TEMPERATURA DO SOLO}

A temperatura do solo exerce influência nas temperaturas internas das zonas, sendo, portanto, necessária a sua definição. Para tanto, utilizou-se o pré-processador do EnergyPlus chamado de "Slab". O Slab pode ser rodado individualmente, antes da simulação no EnergyPlus, ou simultaneamente com a simulação do EnergyPlus (Costa et al., 2017). Neste trabalho foi adotada a primeira opção, e os dados de saída do Slab, correspondente às médias mensais das temperaturas do solo, foram posteriormente inseridos no objeto do EnergyPlus chamado de "Site:BuildingSurfaceGroundTemperature". No Slab, os dados inseridos são apresentados na Tabela 5.

TABELA 5: Dados inseridos no Slab.

\begin{tabular}{|c|c|c|c|}
\hline Número de materiais & 2 & $\begin{array}{l}\text { Calor específico do piso e do } \\
\text { solo }\end{array}$ & $\begin{array}{l}1000 \mathrm{~J} / \mathrm{kg} . \mathrm{K} . \mathrm{e} \\
1200 \mathrm{~J} / \mathrm{kg} . \mathrm{K.} \\
\text { respectivamente }\end{array}$ \\
\hline $\begin{array}{l}\text { Albedo da superfície (com e sem } \\
\text { neve) }\end{array}$ & 0,26 & $\begin{array}{l}\text { Condutividade térmica da } \\
\text { laje e do solo }\end{array}$ & $\begin{array}{l}1,75 \mathrm{~W} / \mathrm{m} . \mathrm{K} \text { e } \\
1 \mathrm{~W} / \mathrm{m} . \mathrm{K} \\
\text { respectivamente }\end{array}$ \\
\hline $\begin{array}{l}\text { Emisssividade da superfície (com e } \\
\text { sem neve) }\end{array}$ & 0,95 & $\begin{array}{l}\text { Relação área/ perímetro do } \\
\text { piso da edificação }\end{array}$ & 1,76 \\
\hline $\begin{array}{l}\text { Rugosidade da superfície (com neve e } \\
\text { sem neve) }\end{array}$ & $\begin{array}{l}4 \text { e } 0,05 \\
\text { respectivamente }\end{array}$ & Espessura do piso & 0,1 \\
\hline $\begin{array}{l}\text { Coeficiente de transferência de calor } \\
\text { por convecção e por radiação com } \\
\text { fluxo vertical (descendente) }\end{array}$ & $\begin{array}{l}6,13 \mathrm{~W} /\left(\mathrm{m}^{2} . \mathrm{K}\right) \text { e } \\
9,26 \mathrm{~W} /\left(\mathrm{m}^{2} . \mathrm{K}\right) \\
\text { respectivamente }\end{array}$ & $\begin{array}{l}\text { Dimensão do domínio } \\
\text { horizontal e vertical do } \\
\text { modelo elaborado }\end{array}$ & 15 (padrão do Slab) \\
\hline $\begin{array}{l}\text { Densidade do material que compõe o } \\
\text { piso e do solo }\end{array}$ & $\begin{array}{l}2300 \mathrm{~kg} / \mathrm{m}^{3} \text { e } \\
1200 \mathrm{~kg} / \mathrm{m}^{3} \\
\text { respectivamente }\end{array}$ & & \\
\hline
\end{tabular}


Ainda, foi levada em consideração nas simulações a evaporação, não foi permitido que o modelo utilizasse uma temperatura fixa ou condição de zero fluxo de calor para o limite inferior do domínio vertical e não foi definido um coeficiente de transferência de calor para a superfície do solo (nesse caso, segundo Costa (2017), o programa calcula o coeficiente de transferência de calor baseando-se nas condições meteorológicas disponíveis). 0 valor de 10 anos foi definido para obter os resultados através de processos iterativos.

\subsection{VENTILAÇÃO NATURAL}

Para este trabalho, foi considerado que a habitação não utiliza aparelhos de condicionamento artificial do ar. Sendo assim, torna-se necessária a simulação da ventilação natural. Para tanto, no EnergyPlus, fez-se uso do objeto "Airflow Network", que permite simular o fluxo de ar direcionado pelo vento (Gu, 2007). O modelo consiste em uma série de nós conectados através de ligações à componentes de fluxos de ar (U.S. Department of Energy, 2016a). Sendo assim, assume-se que o ar flui de um nó para o outro $(\mathrm{Gu}$, 2007).

Os efeitos da ventilação são simulados através do "Airflow Network" por meio de três passos, que envolvem o cálculo de pressões e do fluxo de ar, o cálculo da temperatura dos nós e da umidade, e o cálculo das cargas de calor sensível e latente (U.S. Department of Energy, 2016a). No caso do presente modelo, as zonas representam os nós, enquanto que as aberturas são as ligações de fluxo de ar. A ventilação natural foi inserida nas zonas correspondente à cozinha e lavanderia, à sala de estar e jantar e ao dormitório.

Com relação aos dados de entrada, foi estabelecido que os coeficientes de pressão são calculados pelo programa. Isso é possível devido ao formato retangular da edificação (U.S. Department of Energy, 2016b). O controle da ventilação ocorre através da temperatura. Para que as aberturas sejam acionadas, a temperatura do interior da zona deve maior que a temperatura externa e igual ou maior do que a temperatura de setpoint. No trabalho de Martins et al. (2009), verificou-se que quando a temperatura interna estava em torno de $25^{\circ} \mathrm{C}$, o PMV calculado pelo EnergyPlus tendia a zero. Como este trabalho está analisando o conforto térmico, a temperatura de setpoint foi definida como $25^{\circ} \mathrm{C}$. Por fim, os coeficientes de fluxo de ar e o fluxo de ar através das frestas para as portas e as janelas foram definidos segundo o RTQ-R (INMETRO, 2012), sendo eles 0,65 e 0,001 kg/s.m, respectivamente.

\subsection{PAREDE TROMBE}

Conforme mencionado anteriormente, a partir da segunda simulação foi iniciado o estudo com paredes Trombes. O local definido para inserilas são as paredes norte do dormitório e da sala de estar e jantar, paredes essas que não possuem aberturas no desenho original (Figura 3). As paredes Trombe são formadas por uma camada dupla de tijolos de $19 \mathrm{~cm}$ de espessura, ligadas por $2 \mathrm{~cm}$ de argamassa e rebocadas com 2,5 cm de argamassa de ambos os lados (Tabela 3). Apenas na terceira simulação o reboco externo foi substituído por uma película seletiva, cujas propriedades estão descritas na Tabela 6 .

Os vidros da parede Trombe são duplos, a fim de minimizar as perdas de calor para o exterior. Até a terceira simulação, as paredes Trombe são do tipo não ventilada. Apenas a quarta simulação possui uma parede Trombe ventilada. Essa ventilação também foi definida pelo Airflow Network. Cada esquadria possui dimensões de $3,20 \times 2,80 \mathrm{~m}$ e $15 \mathrm{~cm}$ de profundidade e é inserida por meio de uma zona térmica. Vale ressaltar que, caso esse estudo fosse realizado em outras Zonas Bioclimáticas do Brasil, seria importante estudar também a parede Trombe para resfriamento do ar.

Quando uma zona com parede Trombe é comparada com uma zona normal, observa-se que a primeira possui uma razão de altura por largura muito maior do que a segunda. 


\begin{tabular}{ccccc} 
Espessura (m) & 0,0016 & Calor específico (J/kg.K) & 370,0 \\
\hline Condutibilidade (W/m.K) & 392,61 & Coeficiente de absorção ( $\alpha)$ & 0,85 \\
\hline Densidade $\left(\mathbf{k g} / \mathrm{m}^{\mathbf{3}}\right)$ & 8906,26 & Emissividade (\%) & 0,05 \\
\hline
\end{tabular}

Essa diferença afeta os fenômenos de transferência de calor convectivos fundamentais na zona. Por essa razão torna-se importante a adoção de um algoritmo de convecção especial para a zona com parede Trombe não ventilada (Ellis, 2003). Sendo assim, adotou-se o algoritmo para simulação de paredes Trombe não ventiladas validado por Ellis (2003). Para tanto, este algoritmo deve ser inserido no grupo "Zone" dentro do EnergyPlus.

\subsection{DADOS DE SAÍDA}

Os limites de temperatura de conforto foram definidos conforme o modelo de análise de conforto térmico para ambientes naturalmente ventilados apresentado por Dear e Brager (2002). Neste modelo, chamado de "modelo adaptativo", a temperatura de conforto para edificações naturalmente ventiladas é calculada conforme a Equação 1 (Dear e Brager, 2002).

$$
\mathrm{T}_{\text {conf }}=\left(0,31 \times \mathrm{T}_{\mathrm{a}, \text { out }}\right)+17,8
$$

Em que:

$\mathbf{T}_{\text {conf }}=$ temperatura de conforto $\left({ }^{\circ} \mathrm{C}\right)$;

$\mathbf{T}_{\mathrm{a}, \text { out }}=$ temperatura de bulbo seco externa média $\left({ }^{\circ} \mathrm{C}\right)$;

Para encontrar faixas de temperaturas aceitáveis para $80 \%$ de aceitabilidade geral, devese somar ou subtrair $3,5^{\circ} \mathrm{C}$ da temperatura de conforto para edifícios naturalmente ventilados. Caso seja necessário encontrar a faixa de $90 \%$ de aceitabilidade geral, deve-se somar ou subtrair $2,5^{\circ} \mathrm{C}$.

Neste artigo o desempenho térmico da edificação analisada é mensurado através do nível de conforto térmico proporcionado por ela aos seus ocupantes. O nível de conforto é definido conforme a metodologia descrita por Dear e Brager (2002), considerando 90\% de aceitabilidade geral. Sendo assim, no EnergyPlus são solicitadas como dados de saída a temperatura operativa e a temperatura externa, ambas em dados horários. Posteriormente as temperaturas externas são inseridas na Equação 1. As temperaturas de conforto obtidas com a equação são então comparadas com as temperaturas operativas horárias a fim de verificar em quantas horas do ano essas temperaturas encontram-se dentro da faixa de conforto térmico definida pela Equação 1.

\subsection{CUSTO DO SISTEMA}

Além das análises de conforto térmico, realiza-se também uma análise de custo do sistema. Para tanto, foram consultadas duas empresas especializadas em esquadrias de alumínio localizadas em Curitiba para solicitar um orçamento. Os valores obtidos foram então comparados ao custo estimado da construção da edificação. Esse custo é estipulado multiplicandose a área da residência pelo valor do Custo Unitário Básico da construção civil (CUB) de Curitiba.

\section{RESULTADOS E DISCUSSÕES}

Os resultados apresentados a seguir mostram uma comparação entre a porcentagem de horas em conforto térmico e em desconforto para frio da edificação simulada com uma parede 
comum e com diferentes configurações da parede Trombe. Vale ressaltar que as porcentagens de desconforto para calor foram sempre nulas, e por isso não aparecem nos gráficos. Ainda, são analisadas as variações das temperaturas no interior dos dois ambientes onde foram inseridas as paredes Trombe (sala de estar e jantar e dormitório) em quatro dias selecionados para representar cada uma das quatro estações do ano. Dessa forma, torna-se possível conhecer melhor a influência da parede Trombe no desempenho térmico de edificações.

\subsection{CONFORTO TÉRMICO}

A Figura 5 mostra o resultado de conforto térmico e de desconforto térmico por frio para a sala de estar e jantar. No que diz respeito ao conforto térmico, a melhor configuração foi a parede Trombe ventilada, onde o calor é transferido não somente por condução, através da parede maciça, mas também por convecção, através da movimentação do ar pelas aberturas. 0 uso da parede Trombe permitiu um aumento das condições de conforto térmico em até $16 \%$, o que representa 58 dias a mais em um ano com condições de conforto térmico. Com relação ao acabamento da parede maciça, a película gerou um melhor resultado do que a pintura preta, com um aumento de $11,5 \%$ das horas em conforto térmico, o que demonstra a importância da absorção da parede externa para o correto funcionamento do sistema.

Para o dormitório (Figura 6), os resultados são similares, porém a parede Trombe apresentou uma maior eficiência. Isso porque, apesar das esquadrias possuírem as mesmas dimensões, a porcentagem da área da parede ocupada pelo sistema é maior no caso do dormitório. Nesta situação, o uso da parede Trombe ventilada aumentou o conforto térmico em $22,6 \%$, o que representa 82 dias a mais em um ano com condições de conforto térmico. Quando a película foi inserida, a parede Trombe gerou um aumento de $15,8 \%$ das horas em conforto térmico.

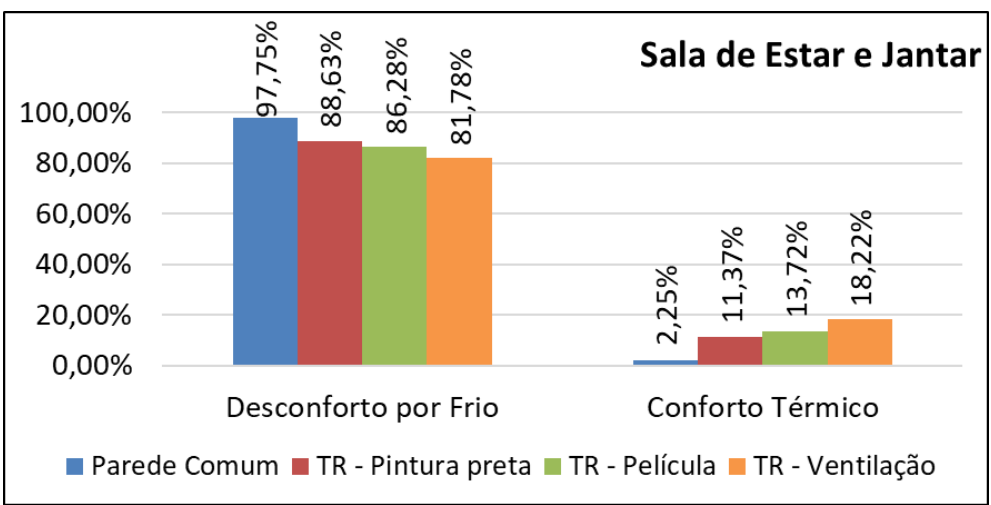

FIGURA 5: Porcentagem de horas em conforto térmico e em desconforto térmico por frio na sala de estar e jantar. A sigla "TR" na legenda indica um ambiente com parede Trombe.

FONTE: Autoria Própria.

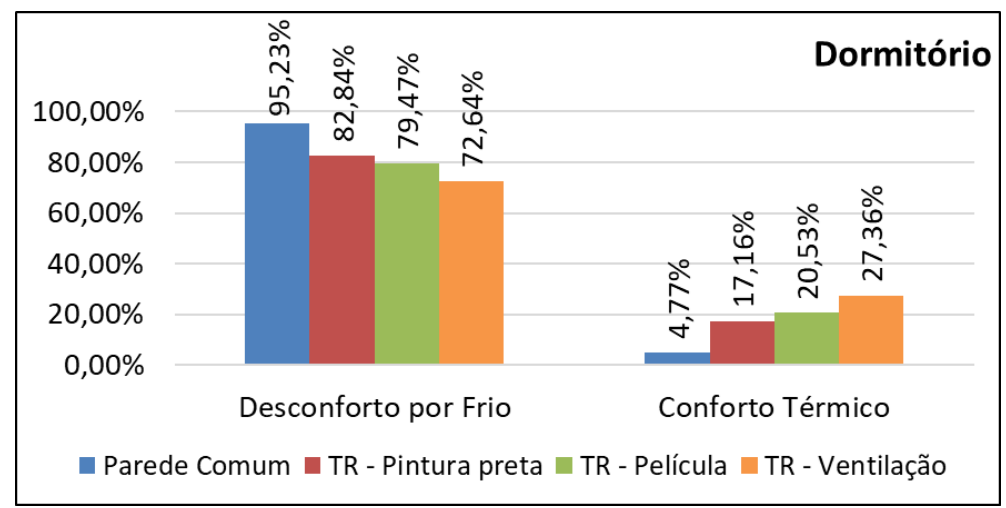

FIGURA 6: Porcentagem de horas em conforto térmico e em desconforto térmico por frio no dormitório. A nomenclatura "TR" indica ambiente com parede Trombe.

FONTE: Autoria Própria. 
Esses resultados comprovam a eficácia da parede Trombe para o clima de Curitiba. Quanto maior a absorção da parede maciça, melhor é o resultado. Ainda, foi comprovado que a movimentação do ar entre a câmera e o ambiente interno é benéfico para o desempenho térmico do sistema. Outro ponto a ser destacado, é a relação direta entre a porcentagem da parede ocupada pela parede Trombe e o desempenho térmico atingido: quanto maior a porcentagem, maior a eficácia do sistema. Essa relação também foi encontrada no trabalho de Cavalcanti (2013). A fim de melhor compreender como varia a temperatura operativa durante um dia nos dois ambientes avaliados, foram analisados quatro dias, cada um deles representando uma das estações do ano (Figura 7).

Os dias selecionados para esta análise foram: equinócio de outono (20 de março), equinócio de primavera ( 23 de setembro), solstício de inverno (21 de junho) e solstício de verão (21 de dezembro). Na Figura 7, observam-se oito gráficos, sendo dois para cada dia avaliado. Além das temperaturas operativas, também foram inseridas as temperaturas de conforto térmico e os limites superiores e inferiores para $80 \%$ e $90 \%$ de aceitação. A área entre os limites superior e inferior para $80 \%$ de aceitação foi destacada em azul. Essas temperaturas foram calculadas conforme metodologia de Dear e Brager (2002).

A partir da Figura 7, pode-se perceber que nos dias de equinócio de primavera e de solstício de inverno, apesar de se atingir temperaturas maiores com o uso da parede Trombe, o sistema não é suficiente para propiciar conforto térmico a seus ocupantes. Possivelmente isso se deve às baixas temperaturas externas que ocorreram nestes dias (temperaturas inferiores à $20^{\circ} \mathrm{C}$ ), o que não é constatado no equinócio de outono e no solstício de verão (Figura 8). Consequentemente, no equinócio de outono e no solstício de verão, a parede Trombe no dormitório mantém as temperaturas operativas internas na zona de conforto durante a maior parte do tempo. Na sala de estar e jantar a zona de conforto é atingida a partir das $10 \mathrm{~h}$ no outono e das $12 \mathrm{~h}$ no verão nestes dois períodos.

No caso do equinócio de outono, tanto na sala de estar e jantar quanto no dormitório, o ambiente com a parede comum se mantém fora da zona de conforto durante todo dia todo o dia. Essa condição é aprimorada gradativamente, passando pelos ambientes com parede Trombe com pintura preta, revestida com a película seletiva e ventilada. A avaliação do solstício de verão leva a conclusões semelhante. Destaca-se aqui que no dormitório a parede Trombe ventilada permitiu que as temperaturas operativas estivessem quase todo o dia de verão e de outono dentro da zona de conforto.

\subsection{ANÁLISE DE CUSTO}

Para realizar a análise de custo, foram consultadas duas empresas localizadas em Curitiba e especializadas em esquadrias de alumínio. 0 preço da esquadria da parede Trombe apresentado pelas empresas foi de $\mathrm{R} \$ 11.806,20 \mathrm{e}$ de $\mathrm{R} \$ 13.440,00$.

Para que se tenha uma ideia do impacto deste valor para o cliente, foi realizado um cálculo simples para estimar o valor da obra utilizando o CUB. Este cálculo consiste em multiplicar o valor do CUB pela área do projeto. Considerando o CUB de 1.799,83 para uma residência unifamiliar, padrão normal (Sinduscon$P R, 2018)$, tem-se uma estimativa de custo da obra de $\mathrm{R} \$ 107.989,8\left(60 \mathrm{~m}^{2} \times 1.799,83\right)$. Isso significa que uma esquadria representaria em torno de 11 a $13 \%$ do valor da obra. Este valor pode ser considerado elevado quando se verifica que em torno de $70 \%$ a $80 \%$ do ano ainda haverá desconforto térmico para frio, e outras soluções deverão ser encontradas. Para que se possa conhecer o quanto este valor impactaria na decisão do usuário, uma pesquisa de aceitação do sistema pelo mercado torna-se necessária. 

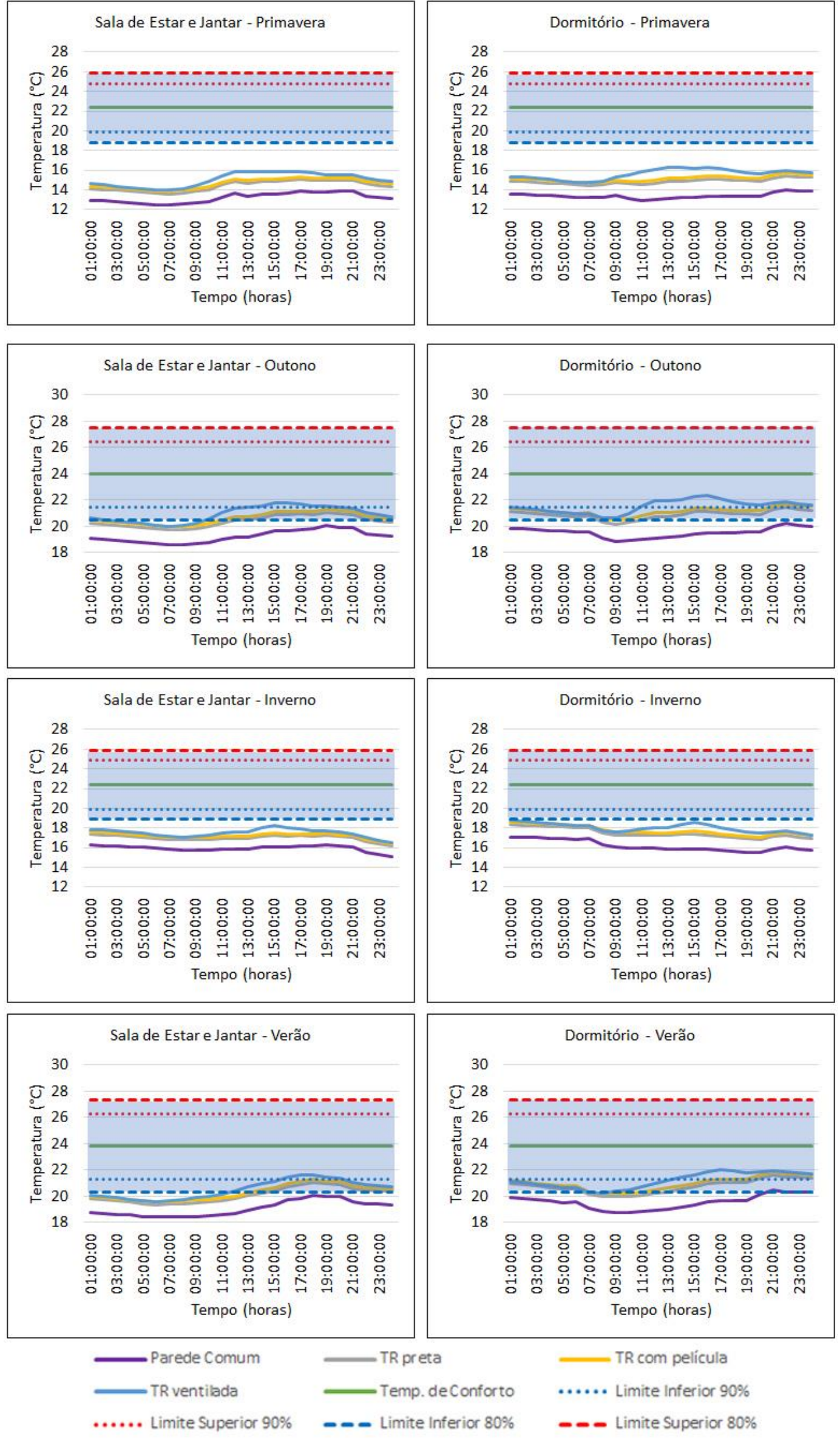

FIGURA 7: Relação entre a temperatura operativa $\left({ }^{\circ} \mathrm{C}\right)$ e o tempo (horas) de quatro dias: equinócio de primavera, equinócio de outono, solstício de inverno e solstício de verão. 


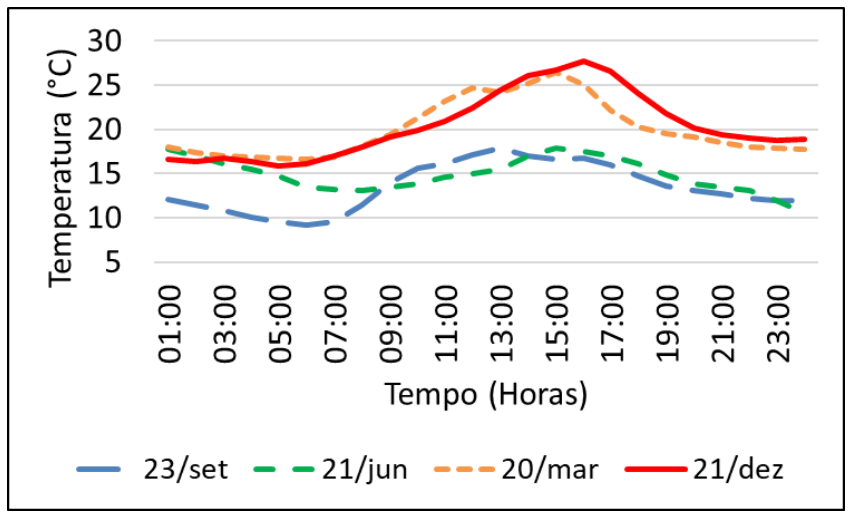

FIGURA 8: Variação da temperatura externa $\left({ }^{\circ} \mathrm{C}\right)$ para os quatro dias avaliados. FONTE: Autoria Própria.

\section{CONSIDERAÇÕES FINAIS}

Neste trabalho analisou-se o desempenho térmico de ambientes com e sem paredes Trombe. Foi avaliado também o impacto de mudanças nos materiais ou na forma de uso das paredes Trombes no conforto térmico dos ocupantes, sempre considerando o clima de Curitiba. A partir das análises realizadas neste artigo, constata-se que o uso de paredes Trombe permitiu a elevação das temperaturas internas, especialmente quando foram abertas as janelas de ventilação interna. A análise mais detalhada mostrou que 0 desempenho térmico do sistema foi melhor nos dias de solstício de verão e de equinócio de outono. Tal fato demonstra que nos dias de temperaturas externas muito baixas o uso da parede Trombe não é suficiente para garantir o conforto térmico dos ocupantes.

O acabamento da superfície externa se mostrou essencial para o correto funcionamento do sistema. Já se sabia que quanto maior a capacidade da superfície absorver energia, maior o desempenho térmico de uma parede Trombe. A partir das simulações foi possível quantificar essa influência. Vale ressaltar que todas as superfícies de uma edificação irão influenciar no conforto térmico. Mudanças na construção da cobertura e das demais paredes da edificação certamente afetariam o resultado final apresentado neste artigo, podendo ressaltar ou minimizar o impacto da adoção da parede Trombe.

Apesar de ter sua eficiência comprovada, constatou-se que o preço da esquadria pode ser um impedimento para a adoção do sistema. Porém, se o objetivo for possuir uma parede envidraçada, possivelmente a adoção de paredes Trombe será uma melhor solução para o clima de Curitiba, já que ela permite uma menor taxa de trocas de calor. Um estudo neste sentido seria interessante. Sendo assim, ressalta-se a importância de uma análise do desempenho da parede Trombe combinada com outras estratégias bioclimáticas. Do contrário, seria necessária a adoção da climatização artificial, o que levaria a mais um investimento por parte do proprietário.

\section{REFERÊNCIAS BIBLIOGRÁFICAS}

ABBASSI, Fakhreddine; DIMASSI, Narjes; DEHMANI, Leila. Energetic study of a Trombe wall system under different Tunisian building configurations. Energy And Buildings, [s.I.], v. 80, p.302-308, set. 2014. Elsevier BV

ABNT - ASSOCIAÇÃO BRASILEIRA DE NORMAS TÉCNICAS, NBR 15220: Desempenho Térmico de Edificações - Parte 2: Métodos de cálculo da transmitância térmica, da capacidade térmica, do atraso térmico e do fator solar de elementos e componentes de edificações. Rio de Janeiro, 2005a.

NBR 15220: Desempenho Térmico de Edificações - Parte 3: Zoneamento bioclimático brasileiro e diretrizes construtivas para habitações unifamiliares de interesse social. Rio de Janeiro, 2005b.

BIANCO, Corina Faria. Parede Trombe: Estudo experimental comparativo de desempenho térmico para aquecimento e arrefecimento na cidade de São Paulo. Tese (Doutorado em Arquitetura) - Faculdade de Arquitetura, Universidade de São Paulo. São Paulo, 2016, $344 \mathrm{f}$. 
BRIGA-SÁ, Ana et al. Energy performance of Trombe walls: Adaptation of ISO 13790. Energy And Buildings, [s.I.], v. 74, p.111-119, maio 2014. Elsevier BV.

CAVALCANTI, F. S., LUKIANTCHUKI, M. A.; ANDRADE, N. C.; PAIVA, R. C.; CARAM, R. M. Parede Trombe como estratégia passiva promotora de eficiência energética em São Carlos-SP. Anais do IV Congresso Brasileiro de Eficiência Energética, 2011, Juiz de Fora, MG.

CAVALCANTI, F. S. Paredes Trombe no Brasil: Análise do potencial de utilização para aquecimento e refrigeração. Tese (Doutorado em Arquitetura) Faculdade de Arquitetura, Universidade de São Paulo. São Carlos, 2013, 144 f.

CAVALCANTI, F. S.; CARAM, R. M. Avaliação do Uso de Fachada Solar no Litoral do Nordeste Brasileiro: O Caso das Paredes Trombe. Revista Brasileira de Energia Solar, v. 4, n.1, 2013, 40-46.

COSTA, V. A. C. da. Trocas de calor entre edificações térreas e o solo e sua modelagem no pré-processador Slab. Dissertação (Mestrado em Arquitetura e Urbanismo). Instituto de Arquitetura e Urbanismo, Universidade de São Paulo, São Carlos, 2017, 237 p.

COSTA, V. A. C. da; RORIZ, V. F.; CHVATAL, K. M. S. Modeling of slab-on-grade heat transfer in EnergyPlus simulation program. Ambiente Construído, v. 17, n. 3, 2017, 117-135.

DEAR, R. de; BRAGER, G. Thermal comfort in naturally ventilated buildings: revisions to ASHRAE Standard 55. Energy And Buildings, v. 34, 2002, 549-561.

ELLIS, P. G. Development and Validation of the Unvented Trombe Wall Model in EnergyPlus. Dissertação (Mestrado em Engenharia Mecânica) University of Illinois at Urbana-Champaign, 2003, $113 \mathrm{f}$.

ENERGYPLUS. EnergyPlus. Disponível em: < https://energyplus.net/ >. Acesso em abril de 2018.

FIGUEIRA, Daniel Sampaio. Análise experimental e numérica do comportamento térmico de um coletor solar acumulador. Tese (Doutorado em Engenharia Mecânica) - Programa de Pós-Graduação em Engenharia Mecânica, Universidade Federal do Rio Grande do Sul, Porto Alegre, 2005, 199 f.

GAN, G. A parametric study of Trombe walls for passive cooling of buildings. Energy And Buildings, $v$. 27, n. 1, 1998, 37-43.

GOMES, Miguel António da Graça. Construção Sustentável - Contributo da Utilização da Parede Trombe. Dissertação (Mestrado em Engenharia Civil Perfil de Construção). Faculdade de Ciências e Tecnologia, Universidade Nova de Lisboa, Lisboa, 2011, $163 \mathrm{f}$.
GU, L. Airflow Network Modeling in EnergyPlus. 10th International Building Performance Simulation Association Conference and Exhibition. Pequim, setembro de 2007.

INMETRO - Instituto Nacional de Metrologia, Normalização e Qualidade Industrial. Portaria $n^{\circ} 18$, de 16 de janeiro de 2012. Regulamento Técnico da Qualidade do Nível de Eficiência Energética Edificações Residenciais. Brasília, DF, 2012.

LABEEE - Laboratório de Eficiência Energética em Edificações. Arquivos climáticos INMET 2016. Disponível em

http://www.labeee.ufsc.br/downloads/arquivosclimaticos/inmet2016 >. Acesso em março de 2018.

LAMBERTS, R.; TRIANA, M. A. Levantamento do Estado da Arte: Energia. Documento 2.2. Projeto: Tecnologias para construção habitacional mais sustentável. Projeto FINEP 2386/04. São Paulo, 2007.

MARTINS, D. J.; RAU, S. L.; RECKZIEGEL, S.; FERRUGEM, A. P.; SILVA. A. C. S. B. da. Ensaio sobre a Automatização de Aberturas na Simulação de Desempenho Térmico de Edificações. Anais do $X$ Encontro Nacional e VI Encontro Latino Americano de Conforto no Ambiente Construído. Natal, 16 a 18 de setembro de 2009.

MENDONÇA, P.J.F. de A.U. de. Habitar sob uma segunda pele: Estratégias para a Redução do Impacto Ambiental de Construções Solares Passivas em Climas Temperados. Tese de Doutorado. Departamento de Engenharia Civil, Universidade do Minho, Guimarães 2005.

MONTEIRO, L. M.; BITTENCOURT, L.; YANNAS, S. 2015. O Edifício Ambiental. In: GONÇALVES, Joana Carla Soares; BODE, Klaus (Org.). Arquitetura da Adaptação. São Paulo: Oficina de Textos, 2015. p. 36-46.

PINTO, A. R.; DIAS, B. Aquecimento solar passivo ganhos diretos, indiretos $\mathrm{e}$ isolados. Revista Arquitectura Lusíada, 7, 2015, 77-92.

ROSSI, Francine A.; DUMKE, Eliane; KRÜGER, Eduardo L. Atualização do Ano Climático de Referência para Curitiba. Anais do X Encontro Nacional e VI Encontro Latino Americano de Conforto no Ambiente Construído. Natal, setembro de 2009.

SINDUSCON-PR. CUB-PR. Disponível em: <https://sindusconpr.com.br/tabela-completa-370-p>. Acesso em março de 2018.

STAZI, F.; MASTRUCCI, A.; PERNA, C. de. The behaviour of solar walls in residential buildings with different insulation levels: An experimental and numerical study. Energy And Buildings, v. 47, 2012, 217-229. 
SUZUKI, E. V. Avaliação do Potencial de Aquecimento / Resfriamento de um Sistema de Climatização Passiva. Dissertação (Mestrado em Engenharia Civil) - Programa de Pós-Graduação em Engenharia Civil, Universidade Tecnológica Federal do Paraná, Curitiba, 2012, 93 f.

U.S. Department of Energy. Engineering Version. Version 8.7., Ernest Orlando Lawrence Berkeley National Laboratory, Berkeley, USA, 2016a.

Input and Output Reference. Version 8.7., Ernest Orlando Lawrence Berkeley National Laboratory, Berkeley, USA, 2016b.

YEDDER, R. Ben, BILGEN, E. Natural convection and conduction in Trombe wall systems, International Journal of Heat and Mass Transfer (1991) 1237-1248. 